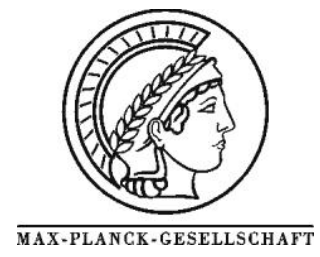

\title{
The mechanochemical stability of hydrogen titanate nanostructures
}

\author{
M. Plodinec ${ }^{1}$, I. Friščić ${ }^{2}$, D. Iveković ${ }^{3}$, N. Tomašić ${ }^{4}$, D. S. Su ${ }^{5}$ J. Zhang ${ }^{6}$, A. Gajović ${ }^{1 *}$ \\ ${ }^{1}$ Ruđer Bošković Institute, Zagreb, Bijenička 54, HR-10000 Zagreb, Croatia \\ ${ }^{2}$ Department of Physics, Faculty of Science, University of Zagreb, Bijenička 32, HR-10000 Zagreb, Croatia \\ ${ }^{3}$ Faculty of Food Technology and Biotechnology, University of Zagreb, Pierottijeva 6, HR-10000 Zagreb, Croatia \\ ${ }^{4}$ Institute of Mineralogy and Petrography, Faculty of Science, University of Zagreb, Horvatovac bb, \\ HR-10000 Zagreb, Croatia \\ ${ }^{5}$ Fritz-Haber-Institute der Max-Planck-Gesellschaft, Faradayweg 4-6, 14195 Berlin, Germany \\ ${ }^{6}$ Institute of Metal Research Chinese Academy of Sciences, 110016 Shenyang, China
}

" Corresponding author: e-mail mailto:gajovic@irb.hr,

Received 26 November 2009; Received in revised form 15 March 2010; Accepted 16 March 2010; Available online 23 March 2010

\begin{abstract}
The structural stability of some nanostructured titanates was investigated in terms of their subsequent processing and possible applications. With the aim to investigate their mechanochemical stability, we applied high-energy ball milling and studied the resulting induced phase transitions. Hydrogen titanates with two different morphologies, microcrystals and nanotubes, were taken into consideration. The phase-transition sequence was studied by Raman spectroscopy and X-ray powder diffraction, while the morphology and crystal structure, on the nanoscale, were analyzed by high-resolution transmission electron microscopy. During the mechanochemical treatment of both morphologies, the phase transitions from hydrogen titanate to $\mathrm{TiO}_{2}$ anatase and subsequently to $\mathrm{TiO}_{2}$ rutile were observed. In the case of hydrogen trititanate crystals, the phase transition to anatase starts after a longer milling time than in the case of the titanate nanotubes, which is explained by the larger particle size of the crystalline powder. However, the phase transition from anatase to rutile occurred more quickly in the crystalline powder than in the case of the nanotubes.
\end{abstract}

Keywords: Titanates; nanotubes; ball milling; structural phase transitions

\section{Introduction}

In recent years, nanostructured titanates, especially titanate nanotubes and nanowires, have drawn significant interest because of their interesting electrical and catalytic properties, which are important in a number of applications. One-dimensional titanate nanotubes and titanate nanowires have high specific surface areas, which makes them especially interesting for applications in solar cells [1 - 4], electronics [5], chemical sensors, hydrogen sensing and storage [6 - 8], (photo)catalysis [9-12], as mesoporous materials for ion exchange [13, 14], and in lithium batteries [15].

The easiest way to produce titanate nanotubes is the hydrothermal method proposed by Kasuga et al. [16], which includes a hydrothermal reaction of $\mathrm{TiO}_{2}$ powder in a concentrated $\mathrm{NaOH}$ solution. Although several crystal structures with different stoichiometries were proposed to describe the structure of titanate nanotubes, most authors agree that titanate nanotubes in protonated form ( $\mathrm{H}$-form) have a hydrogen trititanate monoclinic structure corresponding to the formula $\mathrm{H}_{2} \mathrm{Ti}_{3} \mathrm{O}_{7}$ [17-21]. However, recent investigations based on Raman spectroscopy have provided some evidence that the $\mathrm{H}$-form of the titanate nanotubes has a lepidocrocite-type layered structure, corresponding to the formula $\mathrm{H}_{0.7} \mathrm{Ti}_{1.825} \square_{0.175} \mathrm{O}_{4} \cdot \mathrm{H}_{2} \mathrm{O}$ ( $\square$ : vacancy) [22, 23], proposed for the first time by Renzhi Ma et al. [23]. Hydrogen trititanate in the form of crystalline powder with a ramsdellite-type structure [25] can be synthesized from layered crystalline $\mathrm{Na}_{2} \mathrm{Ti}_{3} \mathrm{O}_{7}$ by the ion exchange of the interlayer sodium cations with $\mathrm{H}_{3} \mathrm{O}^{+}$ions [24]. Because of the high proton conductivity of $\mathrm{H}_{2} \mathrm{Ti}_{3} \mathrm{O}_{7}$, this material has been studied as a potential solid-oxide electrolyte for fuel cells [26] and as sensing material in hydrogen sensors [27]. 
For applications and the further processing of titanate nanostructures, their structural stability is one of the key properties. The influence of temperature on the structure and phase transitions of titanate nanotubes [11, 27-31] and crystalline hydrogen trititanate $[25,27$, and 32$]$ is well understood. The thermal behavior of crystalline $\mathrm{H}_{2} \mathrm{Ti}_{3} \mathrm{O}_{7}$ has been studied by A. Le Bail et al., H.-S. Kim et al., and S. Papp et al. [25, 27, 32]. A. Le Bail et al. [25] found the coexistence of three phases between 100 and $400{ }^{\circ} \mathrm{C}$, which finally transformed to $\mathrm{TiO}_{2}$ rutile at $400{ }^{\circ} \mathrm{C}$. H.-S. Kim et al. [27] found that at $400{ }^{\circ} \mathrm{C}$ only $\beta-\mathrm{TiO}_{2}$ existed in the sample, at $600{ }^{\circ} \mathrm{C}$ the presence of $\mathrm{TiO}_{2}$ anatase was observed, while rutile began to appear at $800{ }^{\circ} \mathrm{C}$. S. Papp et al. [32] observed the collapse of the layered structure of $\mathrm{H}_{2} \mathrm{Ti}_{3} \mathrm{O}_{7}$ after heating the sample to temperatures between 250 and $700{ }^{\circ} \mathrm{C}$, while above $700{ }^{\circ} \mathrm{C}$ a phase transformation to a mixture of anatase and rutile $\mathrm{TiO}_{2}$ was observed. Hydrothermally synthesized, protonated titanate nanotubes transform directly into anatase $\mathrm{TiO}_{2}$ during the heat treatment. Recently, A. Gajović et al. [28] observed that after heating protonated titanate nanotubes to $800{ }^{\circ} \mathrm{C}$ and cooling the sample down to the room temperature, the nanotubes transformed predominantly into rutile $\mathrm{TiO}_{2}$ nanoparticles, but a small amount of anatase $\mathrm{TiO}_{2}$ nanowires was also found in the sample. No evidence for the appearance of the metastable $\mathrm{TiO}_{2}$ (B) phase at lower temperatures was found during that study, in contrast to the findings of E. Morgano Jr. et al [29].

The properties and activity of hydrogen titanates, both in the form of crystalline powders and nanotubes, can be improved by doping, alloying, or modifications with other cations, such as the cations of $\mathrm{Pt}, \mathrm{Eu}, \mathrm{Ru}, \mathrm{Fe}, \mathrm{Zn}, \mathrm{Ni}$ and other metals [4, 12, 33-38]. The simplest method of doping or alloying the material is mechanochemical processing $[39,40]$. This process is usually employed for the synthesis of advanced ceramics [41-45] and in the preparation of catalytic materials [46-48].

During the doping or alloying of material as part of a mechanochemical treatment, the sequences of phase transitions frequently occur simultaneously. The high-energy mechanochemical treatment of $\mathrm{TiO}_{2}$, for example, has been investigated in detail [40, 49-53], where it was shown that high-energy ball milling can be used to induce a phase transition from anatase $\mathrm{TiO}_{2}$ to the high-pressure $\mathrm{TiO}_{2} \mathrm{II}$ phase. Prolonged ball milling then transformed the $\mathrm{TiO}_{2}$ II to rutile $\mathrm{TiO}_{2}$. The high-pressure phase $\mathrm{TiO}_{2}$ II with the $\alpha$ $\mathrm{PbO}_{2}$-type structure (space group $\mathrm{Pbcn}$ ) is irreversibly formed from anatase or rutile at pressures higher than 2.56 GPa [54] and $6 \mathrm{GPa}[55,56]$, respectively. This phase was detected by diffraction techniques and Raman spectroscopy [54, 56-58]. No phase transformations have been observed during the milling of $\mathrm{TiO}_{2}$ rutile. To the best of our knowledge, no investigations of the phase transitions induced by a mechanochemical treatment of hydrogen titanates in either powder or nanotubular form have been reported in the literature so far.

The aim of the present work was to investigate the structural stability of crystalline hydrogen trititanate and titanate nanotubes under the conditions of high-energy ballmilling-induced mechanochemical stress. The structural phase transitions and morphological changes during the mechanochemical treatment of the samples were studied by Raman spectroscopy, X-ray powder diffraction (XRD) and transmission electron microscopy (TEM).

\section{Experimental}

\section{1. Syntheses of materials}

Sodium trititanate $\left(\mathrm{Na}_{2} \mathrm{Ti}_{3} \mathrm{O}_{7}\right)$ powder was synthesized by a conventional solid-state reaction between $\mathrm{TiO}_{2}$ (anatase) and anhydrous $\mathrm{Na}_{2} \mathrm{CO}_{3}$. The reagents were predried at $150{ }^{\circ} \mathrm{C}$ overnight. Next, they were mixed in a stoichiometric ratio of $n\left(\mathrm{Na}_{2} \mathrm{CO}_{3}\right): n\left(\mathrm{TiO}_{2}\right)=1: 3$ and the mixture was calcined at $900{ }^{\circ} \mathrm{C}$. After the first $24 \mathrm{~h}$ of calcination the reaction mixture was ground in a mortar and then recalcined at $900{ }^{\circ} \mathrm{C}$ over the next $24 \mathrm{~h}$. The hydrogen trititanate $\left(\mathrm{H}_{2} \mathrm{Ti}_{3} \mathrm{O}_{7}\right)$ powder was obtained using the ion-exchange method, by suspending $\mathrm{Na}_{2} \mathrm{Ti}_{3} \mathrm{O}_{7}$ powder in a $0.1-\mathrm{M} \mathrm{HCl}$ aqueous solution for 7 days, with the acid changed daily. After the ion-exchange process was completed, the $\mathrm{H}_{2} \mathrm{Ti}_{3} \mathrm{O}_{7}$ powder was thoroughly washed with deionized water and dried overnight at $105^{\circ} \mathrm{C}$.

The titanate nanotubes were synthesized from commercial $\mathrm{TiO}_{2}$ powder (anatase phase, $99.9+\%$ ). A mass of $1.15 \mathrm{~g}$ of $\mathrm{TiO}_{2}$ was treated with an aqueous $\mathrm{NaOH}$ solution $(w(\mathrm{NaOH})=30 \%)$ in a PTFE vessel equipped with a reflux condenser and a magnetic stirrer. The reaction was performed at $130{ }^{\circ} \mathrm{C}$ for $24 \mathrm{~h}$. The raw nanotubes were washed with distilled water and then suspended in $0.1-\mathrm{M}$ $\mathrm{HCl}$ in order to exchange the sodium ions from the nanotubes' structure with $\mathrm{H}_{3} \mathrm{O}^{+}$ions $[18,20]$. The protonated nanotubes were finally washed with distilled water and dried for $12 \mathrm{~h}$ at $75^{\circ} \mathrm{C}$.

\section{2. Mechanochemical treatment of the mate- rials}

Crystalline hydrogen trititanate powder and titanate nanotubes were mechanochemically treated in a highenergy ball mill using identical milling parameters. The milling was performed in air using a Fritisch planetary ballmill, Pulvirisette 6, with the vial and balls made of zirconium dioxide (94\%). The rotational speed of the mill was $500 \mathrm{rpm}$ for all the milling experiments. The ball-topowder weight ratio was chosen to be $1: 10$, while the milling time was varied from $10 \mathrm{~min}$ to $10 \mathrm{~h}$.

\section{3. Characterization}

The Raman spectroscopy measurements were performed using a Dilor 24 triple monochromator with an argon-ion laser Coherent, Innova 400 operating at $514.5 \mathrm{~nm}$ 
for the excitation. An Anaspec doublepass prism premonochromator was used to reduce the intensity of the parasite laser plasma line. The Raman spectra of the ballmilled crystalline hydrogen tritanate and titanate nanotubes were recorded using a laser power of $120 \mathrm{~mW}$. The step of the Raman spectrometer was $2 \mathrm{~cm}^{-1}$. In order to minimize the heating of the samples during the recording of the spectra, the incident laser beam was focused on the line shape.

The X-ray diffraction (XRD) patterns were obtained using a Philips PW 3040/60 X'Pert PRO powder diffractometer, employing $\mathrm{CuK} \alpha$ radiation at $45 \mathrm{kV}$ and $40 \mathrm{~mA}$. The incident beam passed through an X-ray mirror having a divergence slit of $0.5^{\circ}$. The diffracted beam was directed to the detector through the parallel-plate collimator with an equatorial acceptance angle of $0.18^{\circ}$. The step size was $0.02^{\circ}$, with a measuring time of $10 \mathrm{~s} / \mathrm{step}$.

The TEM and HRTEM were performed using Philips CM200 LaB6 and FEG (Eindhoven, the Netherlands) transmission electron microscopes, both operated at 200 $\mathrm{kV}$. For the TEM measurements, the samples were suspended in chloroform and briefly (approximately $1 \mathrm{~min}$ ) sonicated in a low-power ultrasonic bath. The suspension was then dropped onto carbon-coated copper grids and finally dried in air. Based on our previous experience with similar samples, a short sonification of a suspension of titanate nanotubes in chloroform has no influence on the structure or the morphology of the nanotubes.

\section{Results}

\subsection{Raman spectroscopy results}

\subsubsection{Raman measurements of ball-milled crystalline $\mathrm{H}_{2} \mathrm{Ti}_{3} \mathrm{O}_{7}$ powder}

The starting material was crystalline hydrogen tritanate with a monoclinic structure and the space group $C 2 / \mathrm{m}$ $\left(a=16.03 \AA, b=3.75 \AA, c=9.18 \AA, \beta=101.45^{\circ}\right.$ ) [59]. The Raman spectrum of the crystalline sample before the milling shows 18 bands (Figure 1a and b), which can be assigned to monoclinic $\mathrm{H}_{2} \mathrm{Ti}_{3} \mathrm{O}_{7}$ [22, 23]. After 20 minutes of milling, anatase $\mathrm{TiO}_{2}$ bands at 144, 191 and $632 \mathrm{~cm}-1$ were observed. With prolonged milling, the intensity of the bands attributed to crystalline $\mathrm{H}_{2} \mathrm{Ti}_{3} \mathrm{O}_{7}$ decreased, accompanied by a simultaneous increase in the intensity of the anatase and rutile $\mathrm{TiO}_{2}$ bands. The rutile bands at 437 and $615 \mathrm{~cm}^{-1}$ become evident after 60 minutes of milling. After 600 min of milling, the bands of crystalline $\mathrm{H}_{2} \mathrm{Ti}_{3} \mathrm{O}_{7}$ completely disappeared. In the Raman spectrum of the sample milled for $600 \mathrm{~min}$ (Fig. 1a), only one anatase band at 151 $\mathrm{cm}^{-1}$, along with rutile bands at $238 \mathrm{~cm}^{-1}, 437 \mathrm{~cm}^{-1}, 608 \mathrm{~cm}^{-}$ ${ }^{1}$, can be observed, indicating that almost all the anatase transformed to rutile.

With the increase in the milling time, the majority of the Raman bands shifted towards smaller wave numbers, with the exception of the anatase band at $144 \mathrm{~cm}^{-1}$, which shifted towards higher wave numbers with increasing mil- ling time (Fig. 1b). Such an upward shift of the anatase band at $144 \mathrm{~cm}^{-1}$ can be explained by a decrease in the size of the anatase particles [60-62] and the breaking of the $\mathrm{TiO}_{2}$ stoichiometry [63-65]. During the milling process, the band of anatase at $632 \mathrm{~cm}^{-1}$ was overlapped with a rutile band appearing at $611 \mathrm{~cm}^{-1}$, so the resulting band was shifted to the lower position. After $60 \mathrm{~min}$ of milling, the anatase band disappeared completely, and only the rutile band at $611 \mathrm{~cm}^{-1}$ was observed in the Raman spectra.

\subsubsection{Raman measurements of ball-milled titanate nanotubes}

In contrast to the Raman spectrum of the starting crystalline $\mathrm{H}_{2} \mathrm{Ti}_{3} \mathrm{O}_{7}$ sample, the spectrum of starting titanate nanotubes shows only 9 bands (Fig. 1c and d). The Raman bands at 125, 145, 190, 277, 396, 450, 671, 830 and 915 $\mathrm{cm}^{-1}$ are in good agreement with previously reported data $[10,13,14,22$, and 31]. In the Raman spectrum of the titanate nanotubes sample recorded after 20 minutes of highenergy ball milling, characteristic Raman bands of anatase at 144,190 and $515 \mathrm{~cm}^{-1}$ were observed, indicating that the NTs partially transformed to the anatase phase. The phase transition of titanate nanotubes into anatase was completed after 40 minutes of milling. With further milling, after 120 minutes, the phase transition from anatase to rutile started. After 600 min of milling, the rutile bands become more prominent, while anatase bands can be observed at 150 , $199,510 \mathrm{~cm}^{-1}$. The shift of the Raman bands of the titanate nanotubes with the extension of the milling time was analogous to the shift of the bands observed in the case of crystalline $\mathrm{H}_{2} \mathrm{Ti}_{3} \mathrm{O}_{7}$ - the bands shifted toward lower wave numbers, again with the exception of the anatase band at $144 \mathrm{~cm}^{-1}$, which moved toward higher wave numbers with the increase in the milling time.

\section{2. $X R D$ results}

\section{2. 1. XRD of ball-milled crystalline $\mathrm{H}_{2} \mathrm{Ti}_{3} \mathrm{O}_{7}$ powd-} er

The XRD pattern of the crystalline $\mathrm{H}_{2} \mathrm{Ti}_{3} \mathrm{O}_{7}$ powder was in good agreement with monoclinic hydrogen trititanate $\left(\mathrm{H}_{2} \mathrm{Ti}_{3} \mathrm{O}_{7}\right.$, JCPDS file 00-36-0654). After $10 \mathrm{~min}$ of milling, the sample retains the trititanate structure (Fig 2a). The diffraction lines of the crystalline $\mathrm{H}_{2} \mathrm{Ti}_{3} \mathrm{O}_{7}$ are narrow and intense, indicating that the crystallites have a regular crystal lattice and a size that is relatively large compared to the wavelength of the X-rays. A decrease of the diffractionline intensities and a broadening of the lines were observed during the milling process, as is shown in Fig. $2 b$ for the case of the lines at positions $24.46675^{\circ}(\bullet)$ and $36.147^{\circ}(\mathbf{})$ , indicating a decrease in the crystallite size and an increase in the lattice strain. It is reasonable to assume that the strain was induced mainly in the outer parts of the particles [40]. The diffraction-line broadening due to the crystallite size is 
a)
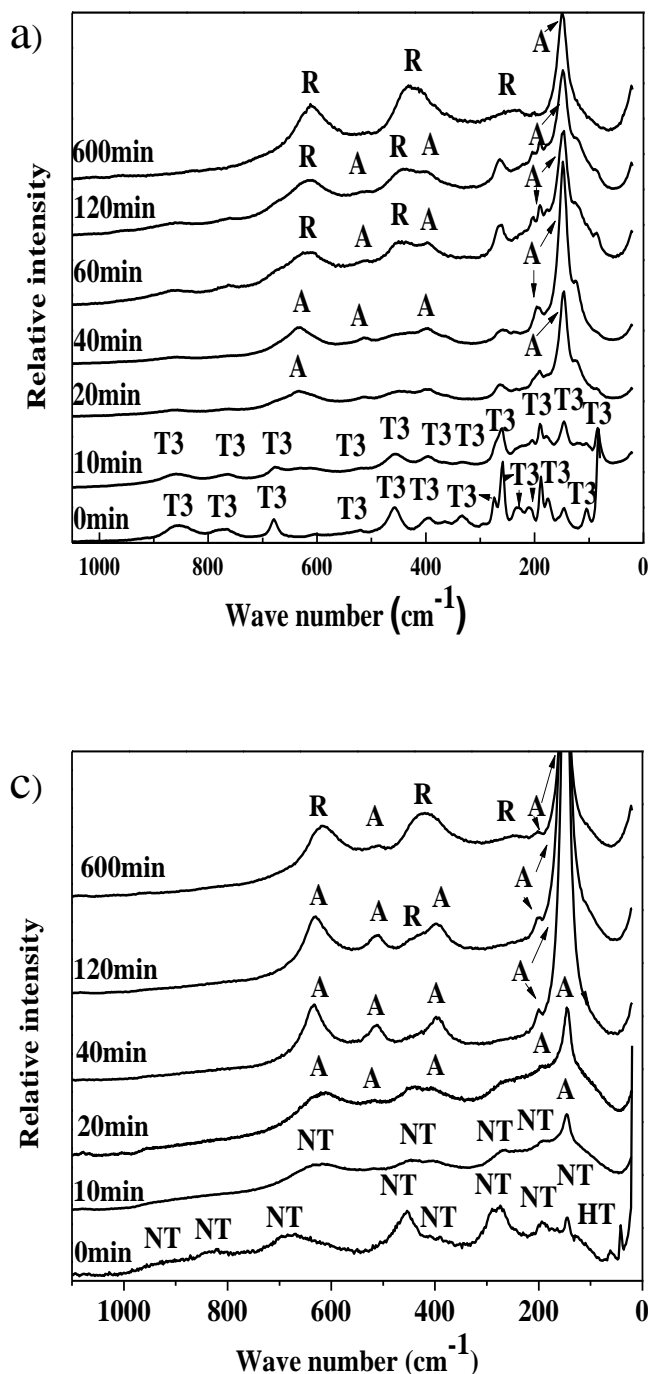
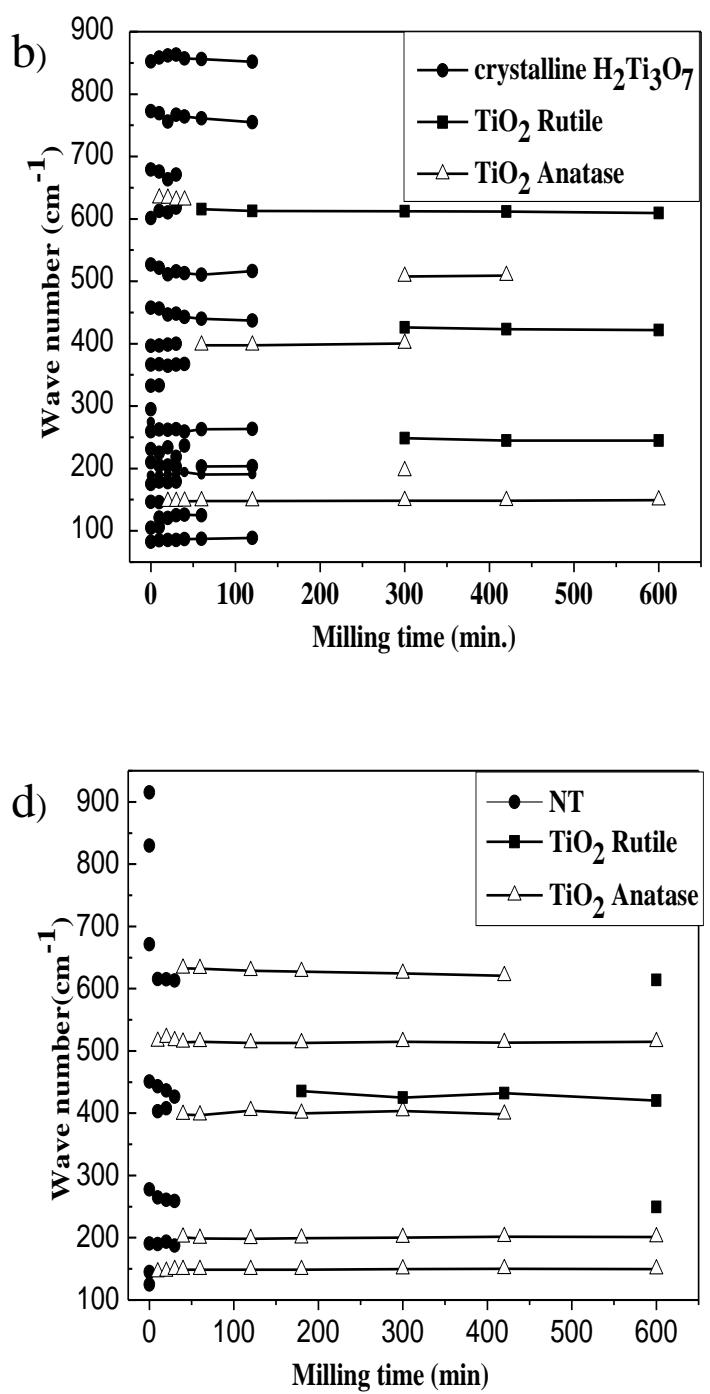

Fig. 1: a) Raman spectra of high-energy ball-milled hydrogen titanate, $\mathrm{H}_{2} \mathrm{Ti}_{3} \mathrm{O}_{7}$ (T3) crystalline powder b) Raman-band positions as a function of milling time of crystalline sample. c) Raman spectra of high-energy ball-milled hydrogen titanate nanotubes (NT). d) Raman-band positions as a function of milling time of nanotubes. $\mathrm{T} 3$ denotes $\mathrm{H}_{2} \mathrm{Ti}_{3} \mathrm{O}_{7}$ bands, A denotes anatase $\mathrm{TiO}_{2}$ bands, $\mathrm{R}$ denotes rutile TiO $\mathrm{O}_{2}$ bands, NT denotes nanotubes bands.

proportional to $1 / \cos \theta$, while the broadening due to the lattice strain is proportional to $\tan \theta(\theta$ being the Bragg angle) $[66,67]$. Thus, in the lower part of the diffraction patterns, shown here, the size effect is more prominent. The listed proportionality $(1 / \cos \theta)$ is confirmed in Fig. 2c. In the case of the sample milled for $20 \mathrm{~min}$, the XRD pattern shows lines of crystalline $\mathrm{H}_{2} \mathrm{Ti}_{3} \mathrm{O}_{7}$, along with lines that can be attributed to anatase (JCPDS file 01-078-2486) and rutile $\mathrm{TiO}_{2}$ (Fig. 2a). In this sample, a non-stoichiometric rutile structure was observed, $\mathrm{Ti} \mathrm{O}_{1.892}(\mathrm{OH})_{0.108}$ (JCPDS file 86-0146), indicating that some $\mathrm{OH}$ groups were still inbuilt between the titanate layers. After milling for $40 \mathrm{~min}$, the stoichiometric rutile (JCPDS file 01-087-0710) was obtained. However, it was not possible to distinguish the dome lines because of overlapping; for example, the lines attributed to the (30-2) and (21-2) planes in $\mathrm{H}_{2} \mathrm{Ti}_{3} \mathrm{O}_{7}$ overlap with the line attributed to the (101) plane in rutile, while the (301), (212), and (104) lines of $\mathrm{H}_{2} \mathrm{Ti}_{3} \mathrm{O}_{7}$ overlap with the (004) line of anatase, the (111) line of rutile, and the (210) line of rutile, respectively. With prolonged milling, the intensity of the lines attributed to crystalline $\mathrm{H}_{2} \mathrm{Ti}_{3} \mathrm{O}_{7}$ decreased and the lines finally disappeared completely. At the same time, the intensity of the diffraction lines attributed to anatase and rutile increased. After 600 minutes of milling, the lines of $\mathrm{H}_{2} \mathrm{Ti}_{3} \mathrm{O}_{7}$ almost disappeared and only the lines of rutile and non-stoichiometric $\mathrm{Na}_{0.8} \mathrm{H}_{1.2} \mathrm{Ti}_{3} \mathrm{O}_{7}$ (JCPDS 48-0693) were still visible.

In the XRD patterns of the samples milled for $20 \mathrm{~min}$ or longer, the line at $2 \theta \approx 28.4^{\circ}$ and another, less intensive line at $2 \theta \approx 31.5^{\circ}$ were observed. These lines could be assigned to $\mathrm{ZrO}_{2}$ (JCPDS file 00-80-0966), originating from a contamination of the sample due to wear in the milling assembly. 
(a)

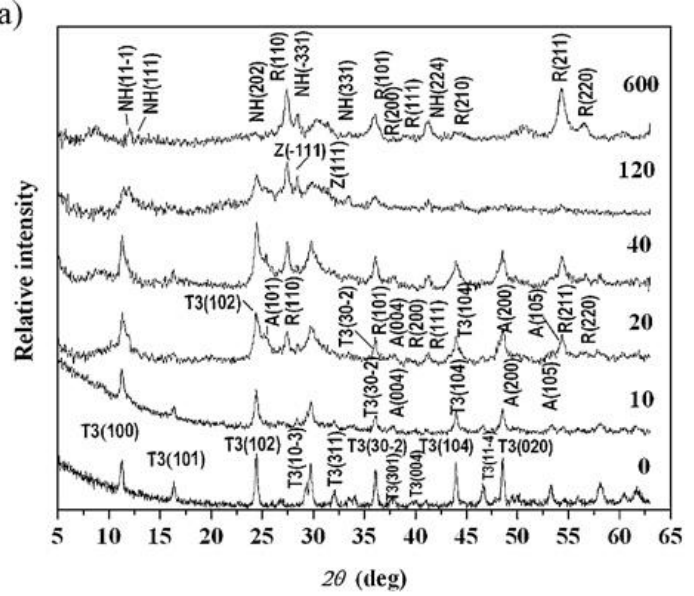

(d)

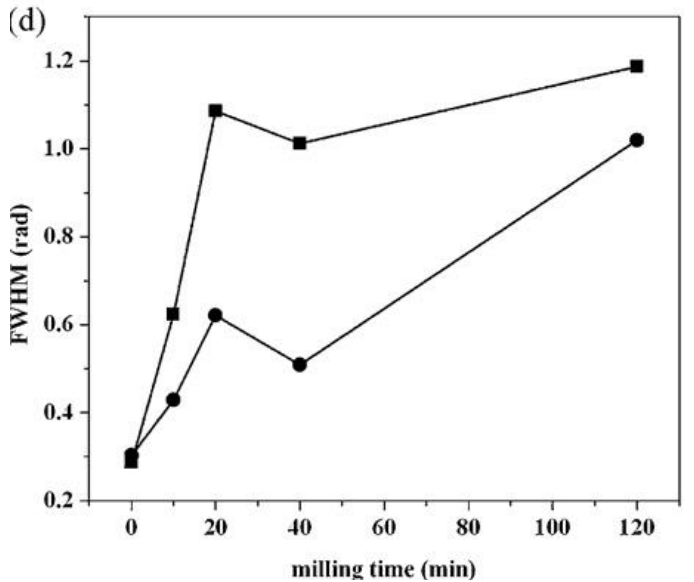

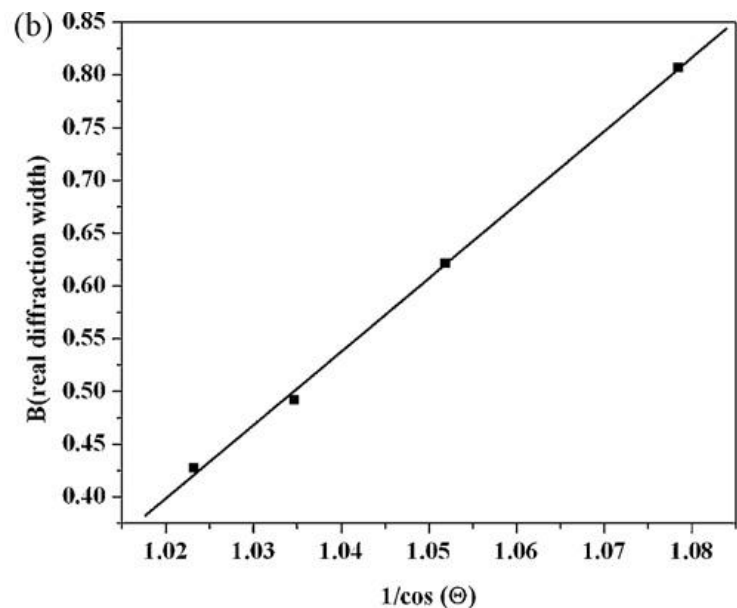

(c)

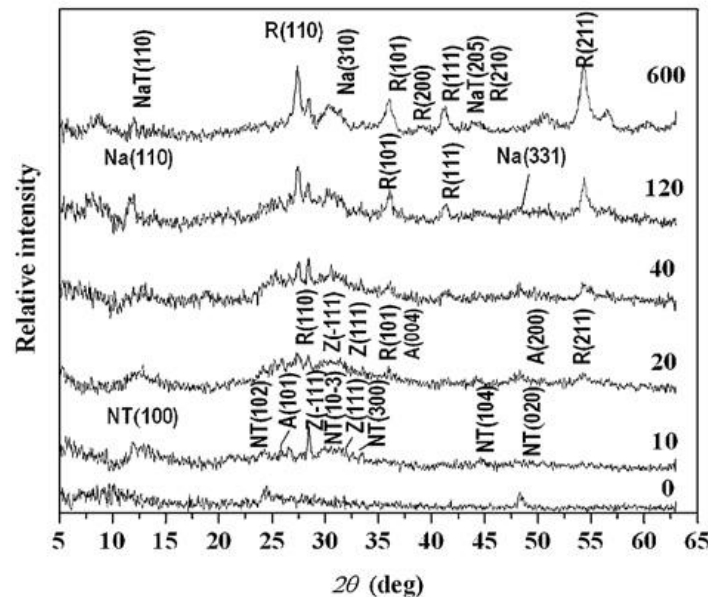

Fig. 2: a) XRD patterns of high-energy ball-milled hydrogen titanate $\left(\mathrm{H}_{2} \mathrm{Ti}_{3} \mathrm{O}_{7}, \mathrm{~T} 3\right)$ crystalline powder, b) Line broadening at half the maximum intensity (FWHM) in radians as a function of milling time for T3 crystalline powder. c) Line broadening at FWHM in radians as a function of $1 / \cos \theta(\theta$ Bragg angle) for T3 crystalline powder sample milled $10 \mathrm{~min}$. d) XRD patterns of high-energy ball-milled hydrogen titanate nano-

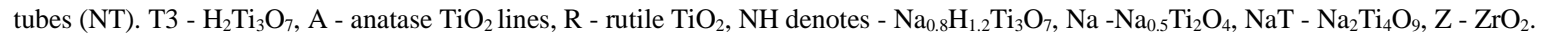

\section{2. 2. XRD of ball-milled titanate nanotubes}

The XRD pattern of the NTs before milling (Fig. 2d) is in good agreement with previous results published by Qian et al. [31]. The nanotubes show weak diffraction lines because of their tubular structure and poor crystallinity [31]. After $10 \mathrm{~min}$ of milling, the lines attributed to anatase appeared in the diffraction pattern of the sample (Fig. 2d), although the dominant features of the pattern were still the lines attributed to the titanate nanotubes. After 20 minutes of high-energy ball milling, non-stoichiometric rutile $\mathrm{Ti}_{0.912} \mathrm{O}_{2}$ (JCPDS 00-089-0553) appeared in the sample. With further milling, the intensity of the anatase and the nanotube lines decreased and the intensity of the rutile lines increased. After 600 minutes of milling, almost all the anatase was transformed to rutile, and the XRD shows very intense rutile lines, which is similar to the XRD observation in the case of milling crystalline $\mathrm{H}_{2} \mathrm{Ti}_{3} \mathrm{O}_{7}$. In this sample, lines of $\mathrm{ZrO}_{2}$ and sodium titanate were observed as well, although these compounds were not expected on the basis of the Raman spectroscopy results.

\section{3. TEM results}

\section{3. 1. TEM of ball-milled crystalline $\mathrm{H}_{2} \mathrm{Ti}_{3} \mathrm{O}_{7}$ powd-} er

Changes in the particle size of crystalline $\mathrm{H}_{2} \mathrm{Ti}_{3} \mathrm{O}_{7}$ induced by high-energy ball milling were investigated by TEM and HRTEM (Fig. 3). The starting sample consisted of crystalline particles with a size of around $300 \mathrm{~nm}$ and well-defined, sharp edges (Fig. 3a). The observed shape indicates that these particles were grown as monocrystals, which is in agreement with the HRTEM image of a small area of the particle (Fig. 3 b). After 10 minutes of milling, the breaking of the crystallites into particles with a size smaller than $100 \mathrm{~nm}$ was observed (Fig 3c). The HRTEM image and the fast Fourier transform (FFT) of the denoted part are shown in (Fig. 3d). Thus, the rings observed in the FFT (inset in Fig. 3d) are assigned as (1- $3.7 \AA \mathrm{H}_{2} \mathrm{Ti}_{3} \mathrm{O}_{7}$ (102), 2 - $3.5 \AA$ : anatase (101), 3 - $3.0 \AA$ : $\mathrm{H}_{2} \mathrm{Ti}_{3} \mathrm{O}_{7}(10-3)$, 4 - $2.5 \AA$ : $\left.\mathrm{H}_{2} \mathrm{Ti}_{3} \mathrm{O}_{7}(30-2), 5-2.1 \AA: \mathrm{H}_{2} \mathrm{Ti}_{3} \mathrm{O}_{7}(104)\right)$. The localized phase transition from the crystalline $\mathrm{H}_{2} \mathrm{Ti}_{3} \mathrm{O}_{7}$ phase to the anatase $\mathrm{TiO}_{2}$ phase occurred on the surface of 

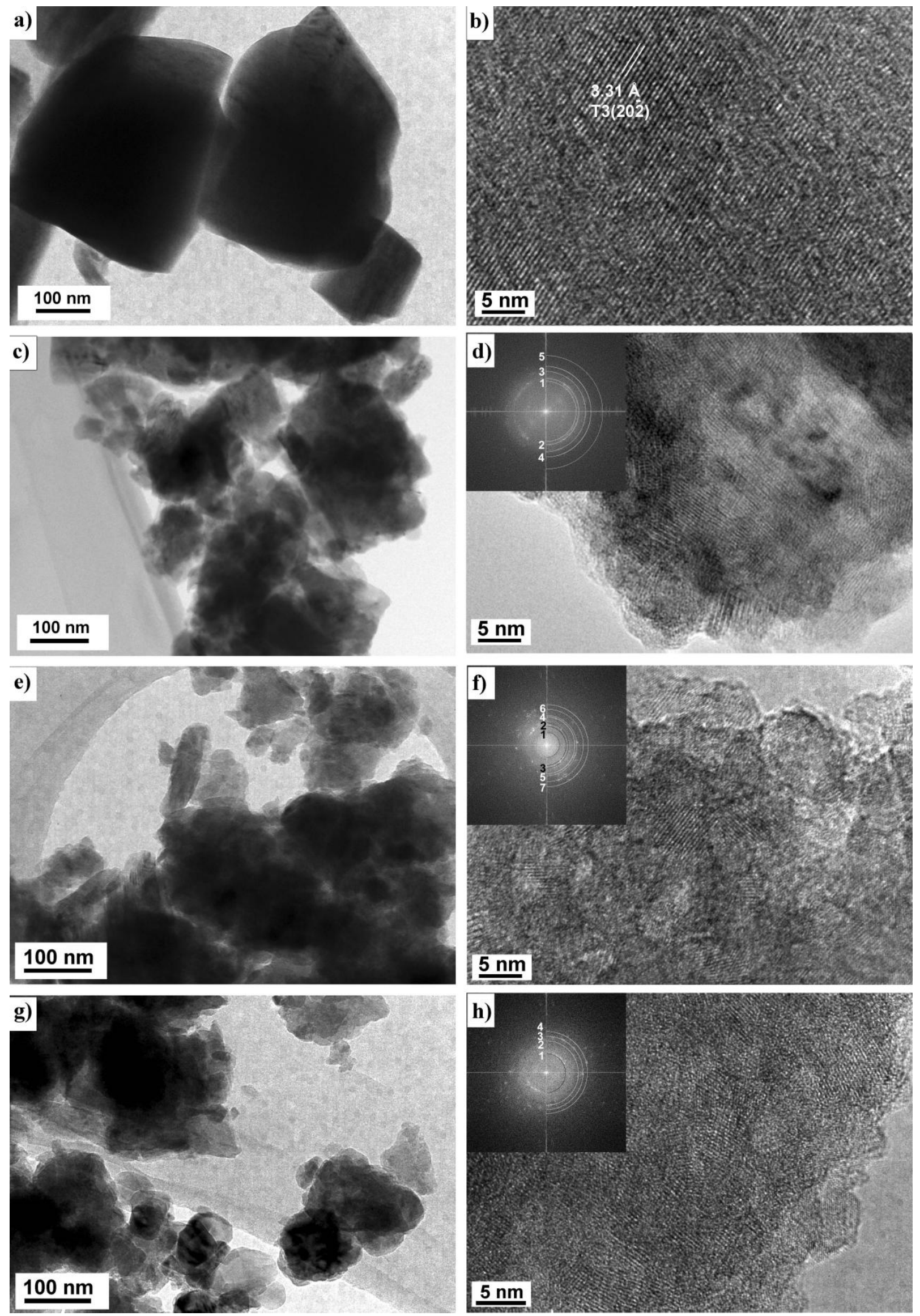

Fig. 3: TEM and HRTEM of hydrogen trititanate crystalline powder. Fast Furier transform (FFT) of the large area of HRTEM images are shown as the insets with denoted rings. a) TEM and b) HRTEM of sample before milling; T3 - presents $\mathrm{H}_{2} \mathrm{Ti}_{3} \mathrm{O}_{7}$; c) TEM and d) HRTEM 10-min milled sample; e) TEM and f) HRTEM 20-min milled sample; g) TEM and h) HRTEM 40-min milled sample. Assignments of the FFT rings are denoted in text. 
the crystals, as indicated by HRTEM image. This localized phase transition was induced by the sporadic impact of the balls on the surface of the $\mathrm{H}_{2} \mathrm{Ti}_{3} \mathrm{O}_{7}$ crystallites. The anatase phase was not observed with Raman spectroscopy or the XRD in the 10-min milled sample.

After $20 \mathrm{~min}$ of milling, the size of the particles decreased further (Fig. 3e), and the phase transition from crystalline $\mathrm{H}_{2} \mathrm{Ti}_{3} \mathrm{O}_{7}$ to anatase and rutile $\mathrm{TiO}_{2}$ continued, as is evident from the FFT shown in the inset of Fig. 3f. The spots are assigned as: $\mathbf{1}-5.4 \AA \mathrm{H}_{2} \mathrm{Ti}_{3} \mathrm{O}_{7}(101), 2-3.5 \AA$ : anatase (101), 3 - $3.0 \AA$ : $\mathrm{H}_{2} \mathrm{Ti}_{3} \mathrm{O}_{7}(10-3), 4-2.4 \AA$ : $\mathrm{H}_{2} \mathrm{Ti}_{3} \mathrm{O}_{7}(30-2)$, anatase (103), rutile (101), 5 - $2.2 \AA$ A: rutile (111), $\mathrm{H}_{2} \mathrm{Ti}_{3} \mathrm{O}_{7}$ (212), 6 - $1.9 \AA \mathrm{A}_{2} \mathrm{Ti}_{3} \mathrm{O}_{7}(020)$, anatase (200), 7 - 1. 7 Å: anatase (105), (211), rutile (211). After 40 minutes of milling, anatase and rutile are the predominate phases present on the surface of particles, as the assignments of the spots in the FFT rings inset in Fig. $3 \mathrm{~h}$ are: $\mathbf{1}-3.5 \AA$, anatase (101); $\mathbf{2}-2.2 \AA$, rutile (111); 3 - $1.9 \AA$ $\mathrm{H}_{2} \mathrm{Ti}_{3} \mathrm{O}_{7}(020)$, anatase (200); 4 - 1. $7 \AA$, anatase (105), (211), rutile (211). The observed spots of crystalline $\mathrm{H}_{2} \mathrm{Ti}_{3} \mathrm{O}_{7}$ in the FFT indicate the existence of regions on the particles' surfaces that were not affected by the impact of the balls during milling (Fig. 3h).

\section{3. 2. TEM of ball-milled titanate nanotubes}

A TEM image of the titanate nanotubes before milling shows particles with a tubular morphology, having an inner radius of approximately $5 \mathrm{~nm}$ and an outer radius of approximately $7 \mathrm{~nm}$, occasionally stacked together in bundles (Fig. 4a). The HRTEM image of the nanotubes' crosssections indicates that the titanate layers are curled 3 to 5 times, so creating the tubes (Fig. 4b). After 10 minutes of milling, some nanotubes were preserved, but some of the nanotubes transformed into agglomerates consisting of smaller nanoparticles (Fig. 4c). The HRTEM and the FFT show that these agglomerates consist of crystallites having the $\mathrm{H}_{2} \mathrm{Ti}_{3} \mathrm{O}_{7}$ or anatase structure (Fig. $4 \mathrm{~d}$ ). The rings observed in the FFT (inset in Fig. 4d) are assigned as: 1- 3.7 $\AA$ : $\mathrm{H}_{2} \mathrm{Ti}_{3} \mathrm{O}_{7}$ (102), 2 - $3.5 \AA$ : anatase (101), 3 - $1.9 \AA$ : $\mathrm{H}_{2} \mathrm{Ti}_{3} \mathrm{O}_{7}(020)$. With further milling, the tubular structures were completely destroyed and transformed into agglomerated particles smaller than $20 \mathrm{~nm}$ in size (Fig. 4e). These particles consisted of $\mathrm{H}_{2} \mathrm{Ti}_{3} \mathrm{O}_{7}$ and anatase crystallites having sizes of approximately $5 \mathrm{~nm}$ (Fig. 4f). The FFT rings in Fig. 4f are assigned as: $\mathbf{1}-5.4 \AA \mathrm{H}_{2} \mathrm{Ti}_{3} \mathrm{O}_{7}(101), \mathbf{2}-3.5$ $\AA$ : anatase (101), 3 - $1.9 \AA \mathrm{H}_{2} \mathrm{Ti}_{3} \mathrm{O}_{7}(020)$. The particle sizes further decreased in the sample milled for $40 \mathrm{~min}$ (Fig. $4 \mathrm{~g}$ and $4 \mathrm{~h}$ ), the spots are assigned as: $\mathbf{1}-3.2 \AA$ A: rutile (110), 2 - $2.4 \AA: \mathrm{H}_{2} \mathrm{Ti}_{3} \mathrm{O}_{7}$ (30-2), anatase (103), rutile (101), 3 - 1. $7 \AA$ A: anatase (105), (211), rutile (211). In this sample, rutile crystallites were observed along with anatase crystallites, as indicated by the HRTEM and FFT shown as an inset of Fig. 4 h.

\section{Discussion}

In this work we have investigated the mechanochemical stability of crystalline $\mathrm{H}_{2} \mathrm{Ti}_{3} \mathrm{O}_{7}$ powder and hydrogen titanate nanotubes. High-energy ball milling was used for the mechanochemical treatment. Raman spectroscopy and XRD (Fig. 1 and 2) showed that, during intensive ball milling, both of these materials transform, first into anatase and then into rutile. The phase transitions of the crystalline $\mathrm{H}_{2} \mathrm{Ti}_{3} \mathrm{O}_{7}$ powder to anatase and then to rutile occurred because the high-energy ball milling generated defects, which influenced the composition and the stoichiometry. In the case of the sample of nanotubes, a smaller number of Raman bands and XRD lines were observed compared to the crystalline $\mathrm{H}_{2} \mathrm{Ti}_{3} \mathrm{O}_{7}$ powder. These bands and lines were broader, having a lower intensity than the crystalline powder, thus indicating the reduced crystallinity of the titanate nanotubes sample. The dehydration of nanotubes, caused by ball-milling, induced a transition of the crystal structure to the anatase phase, accompanied by a degradation of the nanotubes' morphology, as was observed by HRTEM. Considering the importance of the Ti-OH bonding for the stability and formation of nanotubes [31], the removal of the $\mathrm{OH}^{-}$group from the structure causes a degradation of the tubular structure. The Raman band at $266 \mathrm{~cm}^{-1}$ is a consequence of these Ti-OH bonds [31], so its intensity decreased during the ball-milling process.

Both the Raman spectroscopy (Fig. 1) and the XRD results (Fig. 2) demonstrated that during the milling under otherwise identical conditions, the trititanate phase persisted longer in the case of the crystalline $\mathrm{H}_{2} \mathrm{Ti}_{3} \mathrm{O}_{7}$ powder, than in the case of the titanate nanotubes. The small anatase crystallites can be observed by HRTEM in the crystalline $\mathrm{H}_{2} \mathrm{Ti}_{3} \mathrm{O}_{7}$ sample in the early stage of milling, but the appearance of the anatase phase is limited to the part of the $\mathrm{H}_{2} \mathrm{Ti}_{3} \mathrm{O}_{7}$ particles hit by the balls. It is reasonable to assume that the hydrogen titanate crystalline powder needs a longer milling time to complete the phase transitions from $\mathrm{H}_{2} \mathrm{Ti}_{3} \mathrm{O}_{7}$ to anatase because it consists of larger particles than the titanate nanotubes. On the other hand, we observed that during the milling of the titanate nanotubes the anatase phase remains present for a longer time than in the case of the crystalline $\mathrm{H}_{2} \mathrm{Ti}_{3} \mathrm{O}_{7}$.

The influence of milling on the stoichiometry of the resulting phases was evident both from the Raman spectroscopy and the XRD results. During the milling of both the crystalline $\mathrm{H}_{2} \mathrm{Ti}_{3} \mathrm{O}_{7}$ and the titanate nanotubes, the most intensive Raman band of anatase $\left(144 \mathrm{~cm}^{-1}\right)$ moved toward higher wave numbers, indicating the non-stoichiometric composition of the anatase phase [68]. This nonstoichiometry is presumably caused by the breaking up of the particles and the reduction of their size during the intense ball milling. The XRD lines of the rutile phase, which can be observed already after 20 minutes of milling in the case of both samples, can be best matched to nonstoichiometric rutile phases. However, the rutile phase was observed by Raman spectroscopy after 60 and 120 minutes in the crystalline powder and the nanotubes, respectively. 

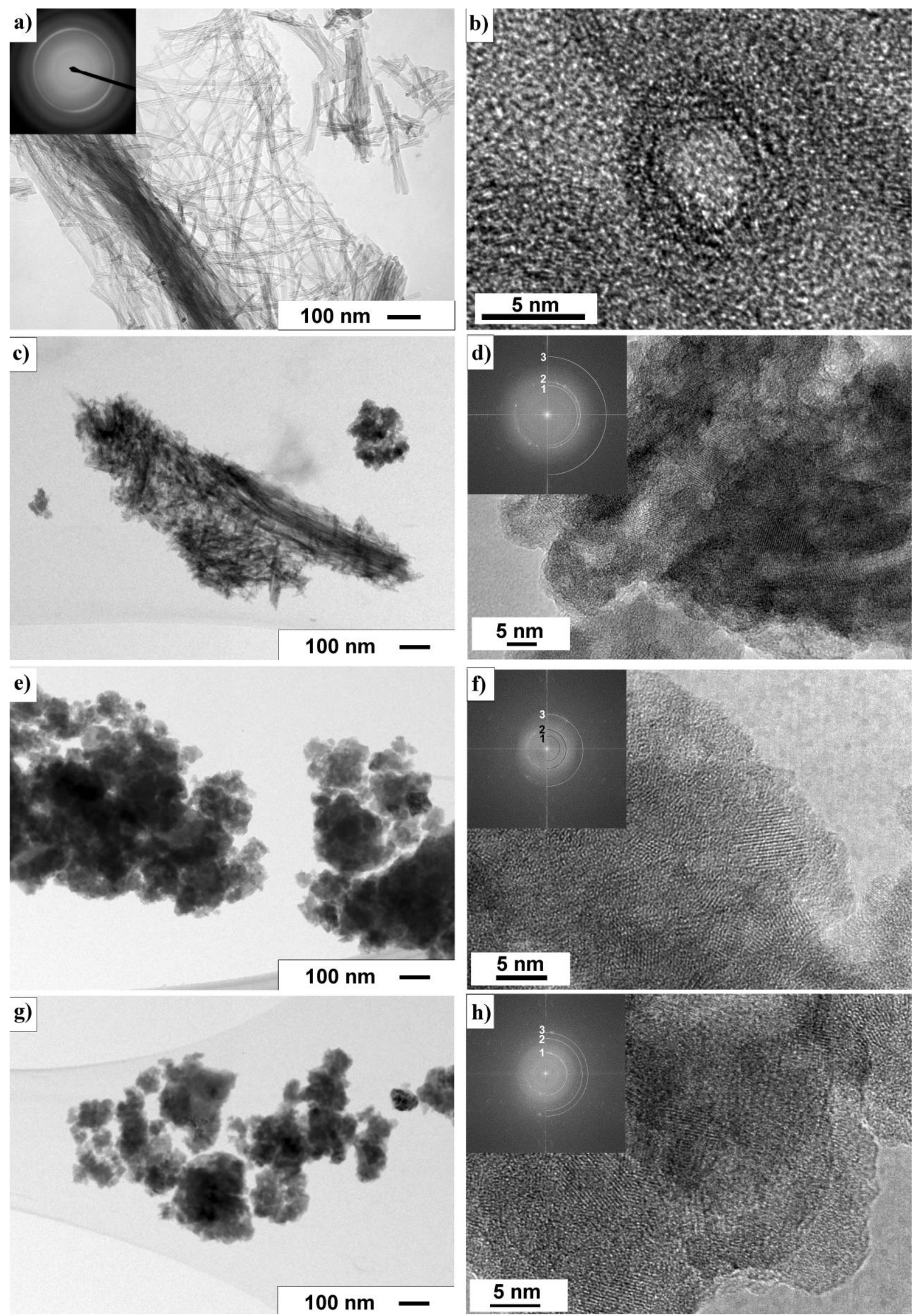

Fig. 4: TEM and HRTEM of hydrogen titanate nanotubes: a) TEM and b) HRTEM of nanotube's cross section before milling; c) TEM and d) HRTEM 10-min milled sample; e) TEM and f) HRTEM of 20-min milled sample; g) and h) milled 40-min. Assignments of the FFT rings are denoted in text. 
These differences between the results obtained by XRD and Raman spectroscopy can be readily explained if we take into account the fact that the XRD responds to changes in the whole volume of the particle, while the Raman spectroscopy is influenced primarily by the changes on the particle surface [40]. Taking this into account it can be assumed that the transition from anatase to rutile starts inside the particles, induced by a local heating of the whole particle volume during milling, and then proceeds toward the surface of particles. The HRTEM observations (Fig 3) support this assumption. In the sample obtained after 20 min of milling the crystalline $\mathrm{H}_{2} \mathrm{Ti}_{3} \mathrm{O}_{7}$, rutile crystallites can be observed on the surfaces of the particles, but these crystallites are small (less than $3 \mathrm{~nm}$ ) and they appear only occasionally. These infrequent, small crystallites are below the detection limit of the XRD. Therefore, the appearance of rutile diffraction lines in the XRD patterns of samples milled for $20 \mathrm{~min}$ can be explained only on the basis that a sufficient amount of rutile phase was formed inside the larger particles. Rutile crystallites grown inside the larger particles cannot be detected by HRTEM, probably because the particles are too thick to achieve a coherence length for the HRTEM observations.

A direct phase transition from anatase to rutile was observed during the milling of both samples. The occurrence of the high-pressure $\mathrm{TiO}_{2}$ II phase during the milling of crystalline $\mathrm{H}_{2} \mathrm{Ti}_{3} \mathrm{O}_{7}$ or titanate nanotubes was not observed by the experimental techniques employed in this work, although this phase normally occurs during the milling of anatase [40, 49-53]. This is surprising, since in this work we employed exactly the same milling conditions as in our earlier ball-milling experiments performed with anatase $\mathrm{TiO}_{2}$ [40], in which the appearance of the $\mathrm{TiO}_{2}$ II phase was already clearly observed. We suppose that during the milling experiments described in this work, a sufficiently high pressure (2.56 GPa [59]), necessary for the formation of the $\mathrm{TiO}_{2}$ II phase, was not reached because a part of the energy released in the impact between the balls and the sample particles was consumed for the dehydration of the $\mathrm{H}_{2} \mathrm{Ti}_{3} \mathrm{O}_{7}$ crystallites and nanotubes.

In order to avoid any contamination of the sample with wear products of the balls and the milling vessel, the milling parameters were carefully chosen, based on the results of our earlier experiments on the ball milling of $\mathrm{TiO}_{2}$ [40]. A ball-to-powder weight ratio of 1:10 was chosen and milling balls and a milling vessel fabricated from a durable material $\left(\mathrm{ZrO}_{2}\right)$ were used. However, the contamination of both samples (crystalline $\mathrm{H}_{2} \mathrm{Ti}_{3} \mathrm{O}_{7}$ and nanotubes) with a small quantity of $\mathrm{ZrO}_{2}$ was observed after longer milling times, as indicated by the appearance of $\mathrm{ZrO}_{2}$ diffraction lines in the XRD of samples milled for $20 \mathrm{~min}$ or longer. Since the crystalline $\mathrm{H}_{2} \mathrm{Ti}_{3} \mathrm{O}_{7}$ and titanate nanotubes have the same crystal structure, it is reasonable to assume that both samples have approximately the same hardness. Therefore, the milling assembly was worn to the same extent during the milling of both samples, explaining why both samples showed approximately the same amount of $\mathrm{ZrO}_{2}$ contamination.
In the sample obtained by milling the crystalline $\mathrm{H}_{2} \mathrm{Ti}_{3} \mathrm{O}_{7}$, the diffraction lines that can be attributed to $\mathrm{Na}_{0.8} \mathrm{H}_{1.2} \mathrm{Ti}_{3} \mathrm{O}_{7}(\mathrm{NH})$ were observed as well (Fig. 2a). The formation of this non-stoichiometric sodium trititanate indicates that the starting $\mathrm{H}_{2} \mathrm{Ti}_{3} \mathrm{O}_{7}$ contained a small amount of residual sodium cations, probably because the $\mathrm{Na}^{+}$ions from the largest $\mathrm{Na}_{2} \mathrm{Ti}_{3} \mathrm{O}_{7}$ particles were not completely ion-exchanged with the $\mathrm{H}_{3} \mathrm{O}^{+}$ions during the preparation of the $\mathrm{H}_{2} \mathrm{Ti}_{3} \mathrm{O}_{7}$. Due to the small content of $\mathrm{NH}$ formed, and since the diffraction lines of crystalline $\mathrm{H}_{2} \mathrm{Ti}_{3} \mathrm{O}_{7}$ have similar positions as the $\mathrm{NH}$ diffraction lines, the diffraction lines of $\mathrm{NH}$ cannot be observed in the samples that contain a substantial amount of $\mathrm{H}_{2} \mathrm{Ti}_{3} \mathrm{O}_{7}$ phase, i.e., in samples milled for a short time. The diffraction lines that can be attributed to $\mathrm{NH}$ were not observed in the samples of titanate nanotubes milled for less than $600 \mathrm{~min}$, probably because the amount of $\mathrm{NH}$, formed from residual sodium ions contained in the sample of starting nanotubes, was much lower than in the case of the crystalline $\mathrm{H}_{2} \mathrm{Ti}_{3} \mathrm{O}_{7}$ powder sample. For both samples, the amount of $\mathrm{NH}$ was too small to be detected by Raman spectroscopy.

\section{Summary}

In the present paper, we studied the stability of crystalline $\mathrm{H}_{2} \mathrm{Ti}_{3} \mathrm{O}_{7}$ powder and hydrogen titanate nanotubes during mechanochemical treatments and showed that the high-energy ball milling of both materials causes phase transitions from the initial structure to anatase $\mathrm{TiO}_{2}$, and with further milling, to the rutile $\mathrm{TiO}_{2}$ phase.

The hydrogen trititanate structure was more resistant to the mechanochemical treatment in crystalline $\mathrm{H}_{2} \mathrm{Ti}_{3} \mathrm{O}_{7}$ powder than in the nanotubes because the powder consisted of larger particles. On the other hand, a direct phase transition from anatase to rutile occurred after a longer milling time in the case of the nanotubes than in the case of the crystalline $\mathrm{H}_{2} \mathrm{Ti}_{3} \mathrm{O}_{7}$ powder.

To get complete information on the phase transitions during the high-energy ball milling, the XRD patterns of the crystalline $\mathrm{H}_{2} \mathrm{Ti}_{3} \mathrm{O}_{7}$ powder and the nanotubes were compared with the Raman spectra and the HRTEM observations, with the conclusion that the phase transition from anatase to rutile starts inside the volume of the particles and then extends to their surface.

The high-pressure $\mathrm{TiO}_{2}$ II phase was not observed during the milling of the samples, although this phase usually appears during the milling of anatase $\mathrm{TiO}_{2}$. This can be attributed to the loss of some of the impact energy, which is expended in the dehydration of the hydrogen titanate structures. A consequence of this is that less pressure is developed during the impact of the milling balls on the sample particles.

Although the milling parameters were carefully chosen in order to avoid any contamination of the sample during the ball milling, contamination due to the wear of the milling assembly (made of $\mathrm{ZrO}_{2}$ ) was observed, indicating 
the considerable hardness of the particles with the hydrogen trititanate structure.

The amount of non-stoichiometric sodium trititanate, formed in the milled samples due to the presence of residual $\mathrm{Na}^{+}$ions in the starting material, was much lower in the case of the nanotubes than in the case of the crystalline $\mathrm{H}_{2} \mathrm{Ti}_{3} \mathrm{O}_{7}$ powder, indicating that the ion-exchange process, employed in the preparation of the samples, was more complete for the case of the nanotubes than for the case of the $\mathrm{H}_{2} \mathrm{Ti}_{3} \mathrm{O}_{7}$ powder.

\section{References}

[1] M. Adachi, Y. Murata, I. Okada, S. Yoshikawa, J. Electrochem. Soc. 150 ((2003) G488-G493.

[2] B. O’Regan, M. Gratzel, Nature 353 (1991) 737-740.

[3] C.J. Barbe, F. Arendse, P. Comte, M. Jirousek, F. Lenzmann, V. Shklover, M. Gratzel, J. Am. Ceram. Soc. 80 (1997) $3157-$ 3171.

[4] J. Xu, J.Yu, M. Zhou, H.Yu, J. Phys. Chem Solids, article in press

[5] F. Croce, G.B. Appetecchi, L. Persi, B. Scrosati, Nature 3944 (1998) 56-458.

[6] O.K. Vardhese, D. Gong, M. Paulose, K.O. Ong, E.C. Dickey, C.A. Grimes, Adv. Mater. 15 (2003) 624-627.

[7] S. Zhang, L.-M. Peng, Q. Chen, G. H. Du, G. Dawson, W. Z. Zhou, Phys. Rev. Lett. 91(2003) 256103.

[8] W.K. Zhang, L.Wang, H. Huang, Y.P. Gan, C.T.Wang, X.Y. Tao Electrochimica Acta 54 (2009) 4760-4763.

[9] S.L. Zhang, J.F. Zhou, Z.J. Zhang, Z.L. Du, A.V. Vorontsov, Z.S. Jin, Sci. Bull. 45 (2000) 1533-1536.

[10] M. Hodos, E. Horvath, H. Haspel, A. Kukovecz, Z. Konya, I. Kiricsi, Chem. Phys. Lett. 399 (2004) 512-515.

[11] S. Sreekantan, L. C. Wei, J. Alloys Compd. 490 (2010) 436 442.

[12] M. W. Xia, L. Wang, X. J. Huan, Y. D. Wu, Z. Dang, J. Alloys Compd. 470 (2009) 486 - 491.

[13] X. Sun, Y. Li, Chem. Eur. J. 9 (2003) 2229-2238.

[14] J.J. Yang, Z.S. Jin, X.D. Wang, W. Li, J.W. Zhang, S.L. Zhang, X.Y. Guo, Z.J. Zhang, Dalton Trans. (2003) 3898 3901.

[15] L. Kavan, M. Kalbac, M. Zukalova, I. Exnar, V. Lorenzen, R. Nesper, M. Graetzel, Chem. Mater. 16 (2004) 477-485.

[16] T. Kasuga, M. Hiramatsu, A. Hoson, T. Sekino, K. Niihara, Langmuir 14 (1998) 3160-3163.

[17] G.H. Du, Q. Chen, R.C. Che, Z.Y. Yuan, L.-M. Peng, Appl. Phys. Lett. 79 (2001) 3702.

[18] Q. Chen, W. Zhou, G. Du, L.-M. Peng, Adv. Mater. 14 (2002)1208-1211

[19] Y.Q. Wang, G.Q. Hu, X.F. Duan, H.L. Sun, Q.K. Xue Chem. Phys. Lett. 365 (2002) 427-431.

[20] Z.-Y. Yuan, B.-L. Su, Colloids Surf. A 241 (2004) 173-183.

[21] A. Thorne, A. Kruth, D. Tunstall, J.T.S. Irvine, W.J. Zhou, Phys. Chem. B 109 (2005) 5439-5444.

[22] Tao Gao, Helmer Fjellvåg, and Poul Norby, Inorg. Chem. 48 (2009)1423-1432..

[23] Renzhi Ma, Katsutoshi Fukuda, Takayoshi Sasaki, Minoru Osada and Yoshio Bando, J. Phys. Chem. B 109 (2005) 6210-6214.norg. Chem. 2009, 48, 142

[24] H. Izawa, S. Kikkawa, M. Koizumi, J. Phys. Chem. 86 (1982) 5023-5026.

[25] A. Le Bail, J.L. Fourquet, Mat. Res. Bull. 27 (1992) 75-85.

\section{Acknowledgements}

The authors wish to thank to the Ministry of Science, Education and Sport of the Republic of Croatia for supporting this work with grants 098-0982904-2898 and 1190000000-1158. The TEM data were obtained using the TEM facility of Fritz Haber Institute of Max Planck Society in Berlin under the financial support by Max Planck Society and a Croatian-German bilateral project.

[26] D.J.D. Corcoran, D.P. Tunstall, J.T.S. Irvine, Solid State Ionics 136-137 (2007) 297-303.

[27] H.-S. Kim, W.-T. Moon, Y.-K. Jun, S.-H. Hong, Sens. Actuators, B 120 (2006) 63-68.

[28] A. Gajović, I. Friščić, M. Plodinec, D. Iveković, J. Mol. Struct. 924-926 (2009) 183-191.

[29] E. Morgado Jr., M.A.S. de Abreu, O.R.C. Pravia, B.A. Marinkovic, P.M. Jardim, F.C. Rizzo, A.S. Araújo, Solid State Sci. 8 (2006) 888-900.

[30] M.A. Cortés-Jácome G. Ferrat-Torres, L.F. Flores Ortiz, C. Angeles-Chávez, E. López-Salinas, J. Escobar, M.L. Mosqueira and J.A. Toledo-Antonio, Catal. Today 126 (2007) 248-255.

[31] L. Qian, Z.L. Du, S.Y. Yang, Z.S. Jin, J. Mol. Struct. 749 (2005) 103-107.

[32] S. Papp, L. Kõrösi, V. Meynen, P. Cool, E. F. Vansant, I. Dékánya, J. Solid State Chem. 178 (2005) 1614-1619.

[33] Z. Tang, L. Zhou, L. Yang, F. Wang, J. Alloys Compd. 481 (2009) $704-709$

[34] N. Murakami, Y. Fujisawa, T. Tsubota, T. Ohno, App. Catalys. B: Environm. 92 (2009) 56-60.

[35] J. Yu, Q. Xiang, M. Zhou, App. Catalys. B: Environm. 90 (2009) 595-602.

[36] D. H. Kim, J. S. Jang, N. H. Goo, M. S. Kwonc, J. W. Lee, Catalysis Today 146 (2009) 230-233.

[37] H. An, J. Zhou, J. Li, B. Zhu, S. Wang, S. Zhang, S. Wu, W. Huang Catalys. Commun. 11 (2009) 175-179.

[38] G. Liu, G. Li, X. Qiu, L. Li, J. Alloys Compd. 481 (2009) $492-497$.

[39] P. Xiaoyan, Jiang Dongmei, L. Yan, M. Xueming, J. Magn. Magn. Mater., 305 (2006) 388-391.

[40] A. Gajovic K. Furic, N. Tomasic, S. Popovic, Z. Skoko, S Music, J. Alloys Compd. 398 (2005) 188-199.

[41] A.M. Bolarin, F. Sanchez, S. Palomares, J.A. Aguilar, G. Torres-Villasenor, J. Alloys Compd. 436 (2007)335-340.

[42] V.V. Zyryanov, V.A. Sadykov, N.F. Uvarov, G.M. Alikina, A.I. Lukashevich, S. Neophytides, J.M. Criado, Solid State Ionics 176 (2005) $2813-2818$.

[43] A. Gajovic, K. Furić, S. Musić, I. Đerđ, K. Furić, D. S. Su, A. Tonejc, A. M. Tonejc, R. Schlögl, J. Am. Ceram. Soc. 89 (2006) 2196-2205

[44] N. Forouzanmehr, F. Karimzadeh, M.H. Enayati, J. Alloys Compd. 478 (2009) 257-259.

[45] Samayamutthirian Palaniandy, Noorina Hidayu Jamil, J. Alloys Compd. 476 (2009) 894-902.

[46] S. Isobea, T. Ichikawab, N. Hanadaa, H.Y. Lenga, M. Fichtnerc, O. Fuhrc, H. Fujiib, J. Alloys Compd. 404-406 (2005) 439-442. 
[47] Jinshu Wanga, Shu Yina, Masakazu Komatsua, Tsugio Satoa, J. Europ. Ceram. Soc. 25 (2005) 3207-3212.

[48] [48] D. Habel, J.B. Stelzer, E. Feike, C. Schröder, A. Hösch, C. Hess, A. Knop-Gericke, J. Caro, H. Schubert, J. Europ. Ceram. Soc. 26 (2006) 3287-3294.

[49] S. Begin - Colin, G. Le Caër, A. Mocellin, M. Zandona, Philos. Mag. Lett. 69 (1994) 1-7.

[50] S. Begin - Colin, G. Le Caër, M. Zandona, E. Bouzy, B. Malaman, J. Alloys Compd. 227 (1995) 157-166.

[51] S. Begin - Colin, T. Girot, G. Le Caër, A. Mocellin, J. Solid State Chem. 149 (2000) 41-48.

[52] P. Bose, S.K. Pradhan, Suchitra Sen, Mater. Chem. Phys. 80 (2003) 73-81

[53] R.M. Ren, Z.G. Yang, L.L. Shaw, J. Mater. Sci. 35 (2000) 6015-6026.

[54] T. Ohsaka, S. Yamaoka, O. Shimomura, Solid State Commun. 30 (1979) 345-347

[55] J. C. Jamieson, B. Olinger, Science 161(1968) 893-895.

[56] J. F. Mammone, S. K. Sharma, Solid State Commun. 34 (1980) 799-802.
[57] H. Arashi, J. Phys. Chem. Solids 53 (1992) 355-359.

[58] K. Lagarec, S. Desgreniers, Solide State Commun. 94 (1995) 519-524.

[59] Q. Chen, G.H. Du, S. Zhang, L.-M. Peng, Acta Cryst. B58 (2002) 587-593.

[60] M. Gotić, M. Ivanda, A. Sekulić, S. Musić, S. Popović, A. Turković, K. Furić, Mater. Lett. 28 (1996) 225-229.

[61] S. Musić, M. Gotić, M. Ivanda, S. Popović, A. Turković, R. Trojko, A. Sekulić, Mater. Sci. Eng. B 47 (1997) 33-40.

[62] M. Gotić, M. Ivanda, S. Popović, S. Musić, A. Sekulić, A. Turković, K. Furić, J. Raman Spectrosc. 28 (1997) 555-558.

[63] W. MA, Z. Lu, M. Zhang, Appl. Phys. A 66 (1998) 621-627.

[64] J. C. Parker, R. W. Siegel, J. Mater. Res. 5 (1990)1246-1252.

[65] J.C. Parker, R. W. Siegel, Appl. Lett. 59 (1990) 943.

[66] B.E. Warren, X-Ray Diffraction. Addison, Reading (1969).

[67] H.P. Klug, L.E. Alexander (1974) X-Ray Diffraction Procedures. John Wiley, New York

[68] J. C. Parker, R. W. Siegel, Appl. Phys. Lett. 57(1990) 943. 